\title{
Estimating of Stearic Acid Dosage Using Self-Propagating Combustion Method in Synthesis of Nanocrystalline $\mathrm{CeO}_{2}$ Powders
}

\author{
Y. MEI, W. C. WANG, H. SUN, W. WANG, Z. R. NIE \\ College of Materials Science and Engineering, Beijing University of Technology, Beijing 100124, China \\ M. S. GAO \\ Zibo Jingze Optical Materials Science and Technology Co. Ltd. , Zibo 255000, China
}

\begin{abstract}
Nanocrystalline $\mathrm{CeO}_{2}$ powders were synthesized using stearic acid and cerium nitrate by sol-gel and self-propagating combustion coupled method. Influence of various molar ratio of stearic acid and cerium nitrate on the products grain and colour were discussed. Powder appearance, crystal phase, specific grain surface and thermal decomposition process of the products were investigated by XRD, SEM, BET and TGDSC techniques. Available quantity of stearic acid needed were calculated by the propellant chemistry concepts and thermodynamics equilibrium, and further tested via the experiments. The results indicated that selfpropagating combustion powders were composed of $\mathrm{CeO}_{2}$ with small size in $100 \mathrm{~nm}$ and purity phase of face centered cubic (FCC), and the best burning effect was gained with the stearic acid and cerium nitrate in a 0.25:1 molar proportion.
\end{abstract}

KEYWORD: Self-Propagating Combustion Method; the Propellant Chemistry Concepts; Thermodynamics Equilibrium; Estimating

\section{GENERAL INSTRUCTIONS}

A beneficial factor of sol-gel method synthesizes the powders by liquid and mixing the reactants at the molecular or atomic level uniformity, while the reaction time gets longer. [1-6] A relatively favorable condition of self-propagating combustion method owns simple operation, high reaction efficiency, a lower cost and simple equipment, but a forward reaction speed, inhomogeneous and easycongregative samples. The combination technique with sol-gel and self-propagating combustion coupled method organically bands the two methods together, overcome each other's shortcomings and exploit the advantages, and the technique has gradually become a recent focus to prepare metal oxide or metal compound oxide at home and abroad in nearly 30 years. [7-11]

\section{EXPERIMENTAL PROCESS}

\subsection{The Sample Preparation}

Stearic acid and cerium nitrate were mixed at molar ratio of $0.15: 1,0.25: 1,0.5: 1,0.75: 1,1: 1,2: 1,3: 1$ and $4: 1$, deionized water as little as possible was joined to dissolve the mixture reactants. The reaction was beginning and going on with continuous stirring at $80^{\circ} \mathrm{C}$, accompanying with the water was vaporized to a colloidal solution, further to transparent gel and till to xerogels. Xerogels was grinded into powder and then baked in muffle at $400^{\circ} \mathrm{C}$ until brown gas gave out and even burned to form arborous yellow powders.

\subsection{Analysis and characteristic of the sample}

Powder XRD of phase and structure was carried out using $\mathrm{CuKa}$ radiations on D8 advance X-ray diffractometer (Germany, BRUKER Co. Ltd). SEM (Hitachi S-3400N II, Japan) was used to characterize the morphology of the particles. Specific surface area and TG-DSC were measured by BET method (ASAP2020, USA) and Thermo Gravimetric Analyzer (STA449C, Germany), respectively.

\section{RESULTS AND DISCUSSION}

\subsection{Product States of Combustion Reaction with Various Molar Ratio of Stearic Acid and Cerium Nitrate}

It was seen from Table 1 that the reaction were all spontaneous combustion and gain the puff yellow powders except a molar ratio in 3:1 of stearic acid and cerium nitrate under the temperature of $400{ }^{\circ} \mathrm{C}$, but a different phenomena on combustion tempestuous degree and colour change. The more 
molar ratio of stearic acid and cerium nitrate, the more incompletion of the autoignition, the weaker of combustion tempestuous degree and the lighter product colour. It implied a great influence of stearic acid dosage on the reaction system. The results concluded that light colour could lead weak absorbency and produce bigger grains. Simultaneity, big particles were ordinarily considered to bring smaller specific surface area and lower materials active because of less exterior atomicity, resulting in lower absorption to the light and lighter colour of the products appeared.[12] The specific surface area of $\mathrm{CeO}_{2}$ particles were confirmed $9.0985 \mathrm{~m}^{2} / \mathrm{g}$ with the stearic acid and cerium nitrate in a molar ratio of $0.25: 1$.

Table 1. Appearances and product states of combustion reaction with different material proportions

\begin{tabular}{|c|c|c|c|}
\hline Molar ratio & Combustion states & Product states & Product colour \\
\hline $0.15: 1$ & \multirow{2}{*}{$\begin{array}{l}\text { autoignition much easily, } \\
\text { high-intensity combustion }\end{array}$} & \multirow{2}{*}{ much puffily } & jacinth \\
\hline $0.25: 1$ & & & sandy beige \\
\hline $0.5: 1$ & \multirow{2}{*}{$\begin{array}{l}\text { autoignition much easily, } \\
\text { active combustion }\end{array}$} & arranging orderly puffy, cone stick & \multirow{2}{*}{$\begin{array}{l}\text { sandy beige upside, } \\
\text { yellow downside }\end{array}$} \\
\hline $0.75: 1$ & & arranging irregular puffy, cone stick & \\
\hline $1: 1$ & \multirow{2}{*}{ autoignition, combustion } & \multirow{2}{*}{ puffy bulk } & \multirow{2}{*}{ yellow } \\
\hline $2: 1$ & & & \\
\hline $3: 1$ & difficult combustion & massy bulk & $\begin{array}{l}\text { light yellow upside, black carbide particles } \\
\text { downside }\end{array}$ \\
\hline
\end{tabular}

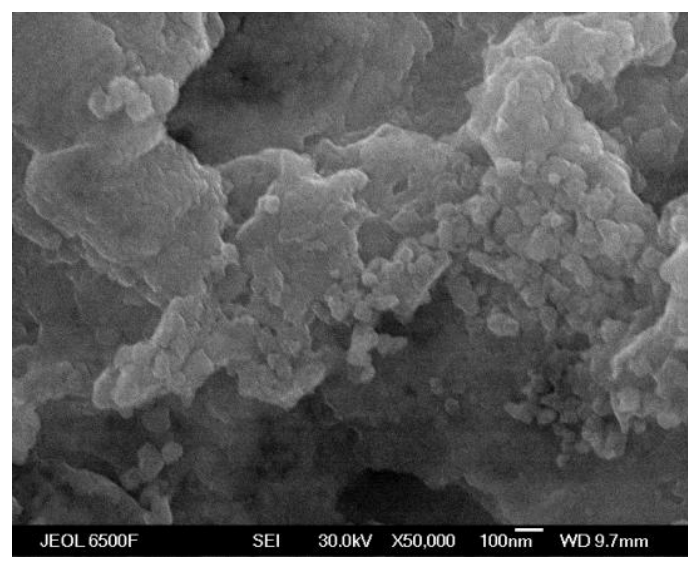

Figure 1. TEM images of the combustion products with the stearic acid and cerium nitrate in a 0.25:1 molar proportion

Figure 1 and Figure 2 showed TEM images and XRD patterns of the combustion products by selfignition with the stearic acid and cerium nitrate in a 0.25:1 molar proportion. The illustrative plates approved the combustion products were ceria with cube well-crystal mould and small spherical-like particles superposition to-gether in the size of $100 \mathrm{~nm}$.

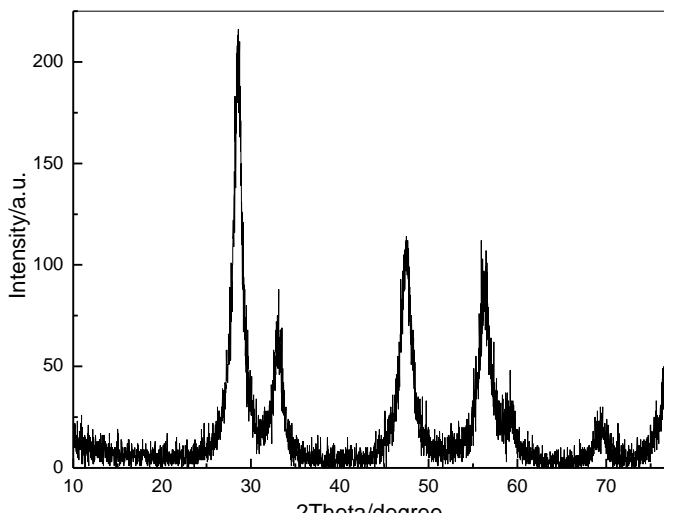

Figure 2. XRD patterns of the synthesized $\mathrm{CeO} 2$ by self-ignition
TG-DSC chart of the products in the same of molar ratio was seen in Figure 3 . The total weightlessness rate seemed only $1.51 \%$ and it was according with the result of $1.485 \%$ by direct weighing method. A sharper decalescence peak at $85.8^{\circ} \mathrm{C}$ was consistent with crystal water evaporation. Subsequently, less weightlessness and heat rate appeared until the temperature arrived $600^{\circ} \mathrm{C}$, which illuminating the organic substance completely burned off and gained pure ceria powders. The experiment made sure the temperature of spontaneous combustion set at $400^{\circ} \mathrm{C}$ was considered reasonably.

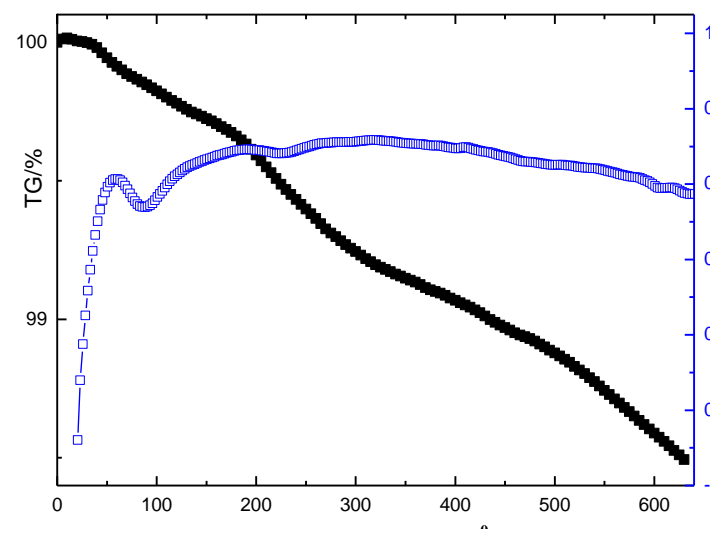

Figure 3. TG-DSC chart of the combustion products at molar ratio of $0.25: 1$ of stearic acid and cerous nitrate

\subsection{Theoretical Calculating Data of Stearic Acid Dosage}

\subsubsection{Theoretical Calculating Data of Stearic Acid Dosage by the Propellant Chemistry Concepts}

It was found that the stearic acid dosage was a main factor in the reaction course through the experiment. The researchers had calculated and concluded stearic acid dosage by "the propellant chemistry concepts", 
which balancing the total oxidizing and reducing valencies in the mixture during the chemical reaction.[13] Here, stearic acid and nitric acid cerium acted as reducer and oxidizer in the course of combustion, respectively. Some element valencies were counted according to the rule, resulting as the valency of carbon element +4 , hydrogen +1 , oxygen 2 , cerium +3 and nitrogen 0 .

Then, the valency of oxidizer nitric acid cerium $\mathrm{Ce}\left(\mathrm{NO}_{3}\right)_{3} 6 \mathrm{H}_{2} \mathrm{O}$ was described as: $+3+3 \times(0-3 \times 2)+$ $6 \times(1 \times 2-2)=-15$, similarly, reducer stearic acid $\mathrm{C}_{18} \mathrm{H}_{36} \mathrm{O}_{2}$ displayed +104 .

The total valency of the chemical reaction will be zero in order to ensure the balance of valency of oxidizer and reducer, then, stearic acid dosage was needed by $n=15 / 104=0.1442 \mathrm{~mol}$. That is to say, stearic acid dosage was ensured to separately provide quantity for the combustion system calculated by stoichiometry.

\subsubsection{Theoretical Calculating Data of Stearic Acid Dosage by the Thermodynamics Equilibrium}

On the other hand, stearic acid dosage of the whole reaction system could be estimated using thermodynamics fundamental. Table 2 was thermodynamics data of the reactants and products.

Chemical reaction below could be taken place during the combustion system:

$$
\begin{aligned}
& \mathrm{Ce}\left(\mathrm{NO}_{3}\right)_{3} \cdot 6 \mathrm{H}_{2} \mathrm{O}(\mathrm{s}) \rightarrow \mathrm{CeO}_{2}(\mathrm{~s})+1.5 \mathrm{~N}_{2}(\mathrm{~g})+3.5 \mathrm{O}_{2}(\mathrm{~g}) \\
& +6 \mathrm{H}_{2} \mathrm{O} \\
& \mathrm{C}_{18} \mathrm{H}_{36} \mathrm{O}_{2}(\mathrm{~s})+26 \mathrm{O}_{2}(\mathrm{~g}) \rightarrow 18 \mathrm{H}_{2} \mathrm{O}(\mathrm{g})+18 \mathrm{CO}_{2}(\mathrm{~g})
\end{aligned}
$$

Total reaction was shown in the following equation and stearic acid dosage was assumed xmol needed:

$$
\begin{aligned}
& \mathrm{Ce}\left(\mathrm{NO}_{3}\right)_{3} \cdot 6 \mathrm{H}_{2} \mathrm{O}(\mathrm{s})+\mathrm{xC}_{18} \mathrm{H}_{36} \mathrm{O}_{2}(\mathrm{~s})+(26 \mathrm{x}-3.5) \mathrm{O}_{2}(\mathrm{~g}) \\
& \rightarrow \mathrm{CeO}_{2}(\mathrm{~s})+1.5 \mathrm{~N}_{2}(\mathrm{~g})+18 \mathrm{H}_{2} \mathrm{O}(\mathrm{g})+18 \mathrm{CO}_{2}(\mathrm{~g})
\end{aligned}
$$

Table 2. Relative thermodynamics data of the reaction

\begin{tabular}{|c|c|c|c|}
\hline Compounds & $\Delta \mathrm{H}_{\mathrm{f}}^{0}\left(25^{0} \mathrm{C}\right)(\mathrm{KJ} / \mathrm{mol})$ & compounds & $\Delta \mathrm{H}_{\mathrm{f}}^{0}\left(25^{0} \mathrm{C}\right)(\mathrm{KJ} / \mathrm{mol})$ \\
\hline $\mathrm{Ce}\left(\mathrm{NO}_{3}\right)_{3} \cdot 6 \mathrm{H}_{2} \mathrm{O}(\mathrm{s})$ & -3047.8 & $\mathrm{CO}_{2}(\mathrm{~g})$ & -393.51 \\
\hline $\mathrm{C}_{18} \mathrm{H}_{36} \mathrm{O}_{2}(\mathrm{~s})$ & -947.7 & $\mathrm{~N}_{2}(\mathrm{~g})$ & 0 \\
\hline $\mathrm{CeO}_{2}(\mathrm{~s})$ & -1088.7 & $\mathrm{O}_{2}(\mathrm{~g})$ & 0 \\
\hline $\mathrm{H}_{2} \mathrm{O}(\mathrm{g})$ & -241.826 & & \\
\hline
\end{tabular}

(s) and (g) express solid state and gas state, respectively.

Enthalpy of reaction (1):

$\Delta \mathrm{Hf}^{0}=3047.8-1088.7=1959.1(\mathrm{~kJ} / \mathrm{mol})$

Enthalpy of reaction (2):

$\Delta \mathrm{Hf}^{0}=-947.7-18 \times(241.826+393.51)=-$ $10488.348(\mathrm{~kJ} / \mathrm{mol})$

The whole systemic reaction should obey law of thermodynamics equilibrium and enthalpy of total reaction would be zero, then:

$\Delta \operatorname{Hf}^{0}\left(25^{\circ} \mathrm{C}\right)=-1959.1-10488.348 \mathrm{x}=0$,

$\mathrm{x}=0.1868 \mathrm{~mol}$.

Stearic acid dosage needed $0.1442 \mathrm{~mol}$ and $0.1868 \mathrm{~mol}$ in the system was calculated by the propellant chemistry concepts and law of thermodynamics equilibrium, respectively. It was obvious that the quantity of thermodynamics equilibrium appeared evident higher than the other. We concluded that the quantity of stearic acid calculated by the propellant chemistry concepts expressed a theoretical dosage supplied the combustion system separately by stoichiometry and kept the reaction entire carrying through. However, enthalpy calculated by thermodynamics equilibrium was required to operate the reaction completely in order to decompose nitric acid cerium entirely and release relevant gas at the temperature of $250{ }^{\circ} \mathrm{C}$, superfluous stearic acid consumed was used for ejective gas taking away a lot of heat in the open air.
In the condition of the actual reaction, more combustion-supporting reagent stearic acid would be needed than theoretical calculating results because the procreant gas would dissipate and take away a mass of heat and consume more reactant. The results showed that the best burning effect was the products with the stearic acid and cerium nitrate in a 0.25:1 molar proportion and it was in accord with deducing.

\section{CONCLUSIONS}

1.The experiment indicated that stearic acid was a good combustion-supporting reagent in preparation of ceria by self-propagating combustion method, resulting in the rapid speed of chemical reaction and quick reaction efficiency.

2. Stearic acid dosage of the combustion reaction could be estimated by theoretical calculation. The system and environment factors should be considered in the course of actual reaction, stearic acid dosage would be higher than the theoretical quantity of thermodynamics equilibrium and the propellant chemistry concepts.

3. The results showed that the best burning effect was the products with the stearic acid and cerium nitrate in a $0.25: 1$ molar proportion. 


\section{ACKNOWLEDGEMENTS}

This wok was financially supported by National 863 Project (2010AA03A407), Beijing Educational Committee Project (PXM201201420400000160) and Zibo Science and Technology Development Plan Project (2014kj100068).

\section{REFERENCES}

[1] Liu, Q. B., Liu Y. F., Ding Y. J., et al. 2014. Synthesis and characterization of novel blue emitting $\mathrm{Na}_{2} \mathrm{CaSiO}_{4}: \mathrm{Ce}^{3+}$ phosphor. Journal of Sol-Gel Science and Technology. 71(2): 276-282

[2] Jia J. G., Liu C. Y., Du P. Y.. 2014. Preparation of Ti doped $\mathrm{BaFe}_{12} \mathrm{O}_{19}$ ceramics by a sol-gel process. Journal of the Chinese ceramic society. 42 (2): 230-236

[3] Ye M. M., Zhang Q., Hu Y. X., et al. 2010. Magnetical-ly recoverable core-shell nanocomposites with enhanced photocatalytic activity, Chem Eur J. 16: 6243-6250.

[4] Xin T. J., Zhang H. P., Ma M. L., et al. 2014. Preparation and characterization of $\mathrm{Fe}_{3} \mathrm{O}_{4}-\mathrm{TiO}_{2}$ core-shell magnetic nanomaterials. Functional Materials. 45 (1): 1072-1077

[5] Xu D., Jiang B., Cui F. D., et al. 2014. Microstructure and electrical properties of $\mathrm{La}_{2} \mathrm{O}_{3}$-doped $\mathrm{ZnO}$-based varistor thin films by sol-gel process. J. Cent. South Univ.. 21: $9-13$

[6] Xu D., Zhang C., Lin Y. H., et al. 2012. Influence of zinc on electrical and microstructural properties of $\mathrm{CaCu}_{3} \mathrm{Ti}_{4} \mathrm{O}_{12}$ ceramics prepared by sol-gel process. Journal of Alloys and Compounds. 522: 157-161

[7] Ringuede A., Labrincha J. A., Frade J. R. 2001. A combustion synthesis method to obtain alternative cermet materials for SOFC anodes. Solid State Ionics. 141-142: 549-557

[8] Marjan Marins`ek, Klementina Zupan, Jadran Mae`ek. 2002. Ni-YSZ cermet anodes prepared by citrate/nitrate combustion synthesis. Journal of Power Sources. 106 : 178-188

[9] Ringuede'A., Bronine D., Frade J.R.. 2002.Assessment of $\mathrm{Ni} / \mathrm{YSZ}$ anodes prepared by combustion synthesis. Solid State Ionics. 146: 219-224

[10] Chinarro E., Figueiredo F. M., Mather G. C., et al. 2007. Combustion synthesis and characterisation of Ni-MOYSZ $\left(\mathrm{M}=\mathrm{Mg}, \mathrm{Ca}, \mathrm{Al}_{2 / 3}\right)$ cermet anodes for SOFCs. Journal of the European Ceramic Society. 27: 4233-4236

[11] Liang M. D., Yu B., Wen M. F., et al. 2010. Preparation of NiO-YSZ composite powder by a combustion method and its application for cathode of SOEC. International journal of hydrogen energy. 35: 2852-2857

[12] Yuan J. R., Li Y. Q., Deng X. H.. 2006. Study on the Light Absorption Properties of Nano-Zn O. Journal of Nanchang University (Engineering \& Technology). 28 (4): 329-331.

[13] Furno D. A., Jurado J. R., Segadaes A. M., et al. 1997. Combustion synthesis of iron-substituted strontium titanate perovskites, Materials Research Bulletin. 32 (10): 1459-1470. 